\title{
Prediction of tidal excursion length in estuaries due to the environmental changes
}

\author{
*J. Parsa; A. Etemad Shahidi
}

School of Civil Engineering, Iran University of Science and Technology, Tehran, Iran

Received 9 November 2009; $\quad$ revised 25 March 2010; accepted 17 April 2010; available online 1 September 2010

\begin{abstract}
Tidal excursion is an important parameter that indicates hydraulic and mixing characteristics of estuarine environments. Prediction of the tidal excursion length provides a proper tool for environmental management of estuaries. In this study, the governing equations of the salinity transport were scaled first to recognize the effective dimensionless parameters of tidal excursion length. Then, a laterally averaged two-dimensional numerical model called CE-QUAL-W2 was used as a virtual laboratory to simulate the salinity intrusion length. Existing field data of Limpopo estuary, as a case study, was used for calibration and verification of the model and reasonable agreement was observed between the model results and the field data. Finally, the verified model was used to assess the influences of the governing parameters. The results showed that simple power functions can be used to describe the effects of dimensionless parameters obtained by scaling of the governing equations. As a result, a new formula in form of a power function was derived to predict the tidal excursion length based on the geometric and hydrodynamic characteristics of alluvial estuaries. Comparison of the computed tidal excursion lengths using the derived formula with the observed measurements in several estuaries showed the robustness of the developed formula.
\end{abstract}

Keywords: Alluvial estuaries; Environmental management; Numerical simulation; Scaling; Tidal range; Water quality

\section{INTRODUCTION}

An estuary is a semi-enclosed coastal water body connecting riverine and saline environments. Estuaries are the main water resources along the coastlines. Since estuaries are among the most productive ecosystems on earth, they have been amongst the most populated areas in the world. Nowadays, more than $50 \%$ of the world population lives along the estuaries and coastlines (Lindeboom, 2002). Estuaries are also considered as an especial ecosystem, due to the existence of tidal condition and brackish water. The multiple use of estuarine water indicates the importance of water quality of estuaries. Changes in water quality conditions have severe environmental impacts on the estuarine ecosystem (Nouri et al., 2008; 2009). The estuarine salinity is as an indicator of water quality for both organism distribution and water consumptions criteria (Jassby et al., 1995; Attrill, 2002; Reinert and Peterson, 2008). Salinity distribution in an estuary is affected by morphologic, bathymetric and hydrodynamic characteristics (Abbaspour et al., 2009).

*Corresponding Author Email: jparsa@iust.ac.ir Tel:+ 98217391 3170; Fax: +9821 73913170
As estuaries are affected by both marine and riverine influences, their salinity and water quality depend strongly on the riverine discharge, tidal fluctuation and the amount of salinity originated from the ocean (Karbassi et al., 2007; Biati et al., 2010; Sundararajan and Natesan, 2010). The salinity variation in an estuary is influenced by tidal level, bathymetry, channel friction and riverine discharge (Mooraki et al., 2009). These environmental changes, which can be due to the manmade or/and natural changes affect the water quality and salinity intrusion, biological and environmental characteristics of estuaries. One of the most interesting environmental issues in the estuaries is determination of salinity intrusion length, which is the length from the mouth to a point in which the salinity is approximately the same as riverine water salinity. Salinity intrusion length varies periodically during a tidal cycle. The maximum and minimum salinity intrusion length occur in high water slack (HWS) and low water slack (LWS), respectively. The difference of salinity intrusion lengths between HWS and LWS is defined as tidal excursion length. An estuary can be divided into three 
different zones based on the salinity contents. The first zone is completely saline and its salinity always is more than riverine water salinity. In the second zone, which coincides with the tidal excursion length, salinity varies periodically between freshwater and brackish water salinity. The third zone is always fresh and its salinity is the same as riverine water salinity. The major feature of the second zone may be its importance for water consumption, e.g. drinking. Savenije (1992) showed that the product of the tidal excursion length and the cross-sectional area at the estuary mouth is a good approximation for the tidal prism. Recent work of Savenije (2005) implied that the tidal excursion length is an important parameter, indicating the hydraulic and mixing mechanism of estuaries. He also showed that the tidal excursion length can be used to estimate the dispersion coefficient and its longitudinal variation along an estuary. Tidal excursion length also can be used as a length scale in the modeling of sediment transport in estuaries (Schramkowski et al., 2002; Hibma et al., 2003; Kho et al., 2009). Schuttelaars et al. (2004) showed that morphodynamic equilibrium depends on the ratio of estuary width to the tidal excursion length (Panjeshahi and Ataei, 2008). Most of the studies on the estuaries have focused on the salinity intrusion length. Although several attempts have been carried out to predict the salinity intrusion length in different situation (e.g. Van der Burgh, 1972; Rigter, 1973; Savenije, 1993; Parsa et al., 2007). Unfortunately, there is limited comprehensive study on the tidal excursion context. Most of the studies on the salinity in estuaries present the salinity intrusion length in LWS, TA (tidally averaged), and HWS. These investigations mainly used empirical models to predict the salinity intrusion length (e.g. Van der Burgh, 1972; Rigter, 1973; Fischer, 1974; Savenije, 1993). Among these studies, only Savenije (1993) studied the tidal excursion length in real estuaries.

The overall objective of the study is to provide a rapid tool in alluvial estuaries to assess the environmental impacts of anthropogenic and natural environmental changes. The main thrust of the present paper is to derive a formula to predict the tidal excursion length using scaling argument and numerical modeling (Mirbagheri and Hashemi Monfared, 2009). Unlike the previous studies, which are mostly obtained by integrating a simple sinusoidal wave function over a tidal cycle, a scaling approach is used in this work. Further, the focus is on the alluvial estuaries, which covers most of estuaries worldwide.

Tidal excursion length is the net horizontal distance traveled by a water particle from LWS to HWS or vice versa. It can be used to describe the movement of pollutants in estuaries during a tidal cycle (Zhen-Gang, 2008). The traditional relationship for estimation of the tidal excursion length is obtained by integrating a sinusoidal tidal velocity over a half of tidal cycle (e.g. Thomann and Mueller, 1987; Savenije, 2005; ZhenGang, 2008). In this way, the tidal excursion length is the twice of tidal velocity amplitude divided by the tidal frequency:

$$
E=\frac{v_{\circ} T}{\pi}
$$

In which, $E$ is the tidal excursion length, $U_{o}$ is the tidal velocity amplitude and $T$ is the tidal period. Most of natural estuaries have an exponentially varying width, depth and cross-sectional area (Wright et al., 1973; Dyer, 1986; Prandle, 1986; Savenije, 1993). Based on Savenije's (1993) observations from 15 estuaries worldwide, most of the alluvial estuaries have constant depth and exponentially varying width. Savenije (1993) conducted an extensive study on the salinity intrusion mechanism in the alluvial estuaries. He solved the advection-diffusion equation analytically to derive an empirical model to predict the salinity intrusion length. Savenije (1993) utilized the following exponential functions to express the longitudinal variation of crosssectional area and width in the alluvial estuaries:

$$
\begin{aligned}
& A=A_{\circ} \exp \left(-\frac{x}{a}\right) \\
& B=B_{\circ} \exp \left(-\frac{x}{b}\right)
\end{aligned}
$$

Where, $A$ and $B$ are the cross-sectional area and the width of estuary at a distance $x$ from the mouth, respectively. $A_{o}$ and $B_{o}$ denote the relevant variables at the mouth, $a$ is the cross-sectional area convergence length and $b$ is the width convergence length.

Since Savenije's (1993) model contains calibration coefficients resulting from assumptions made in their derivation, he carried out numerical simulations for a wide range of hydraulic and geometric conditions. Based on his scaling and the model results, he arrived at the following relationship for the tidal excursion length (Savenije, 1992; 1993): 


$$
E=1.08 \frac{v_{\circ} T}{\pi}
$$

Savenije (1992; 1993; 2005) emphasized the importance of the bathymetry effects on the estuarine mixing mechanism. Therefore, in this study, the effects of various hydraulic and geometric parameters on the tidal excursion length are examined to realize the relationship between these parameters and tidal excursion. This study was carried out in the Department of Water Engineering, School of Civil Engineering, Iran University of Science and Technology in 2008-2009.

\section{MATERIALS AND METHODS}

Scaling analysis involves a systematic method for non-dimensionalizing the dependent and independent variables in a set of describing equations for a physical process. The dimensionless governing equations involve the effective dimensionless groups that are optimal for correlating experimental or numerical data and extrapolating known empirical equations (Krantz, 2007). Furthermore, given certain inputs based on experimental observations or data, scaling analysis can be used to derive empirical relationships; which would otherwise be quite difficult, if not impossible to arrive at.

In this study, scaling analysis is used to emerge the effective dimensionless parameters in the tidal excursion length. It is assumed that salinity in the vertical direction is approximately constant along the entire estuary. In order to obtain the relevant dimensionless groups, following equations for tidal movement and mass balance are considered:

$B \frac{\partial h}{\partial t}+\frac{\partial A u}{\partial x}=0$

$\frac{\partial u}{\partial t}+u \frac{\partial u}{\partial x}+g \frac{\partial h}{\partial x}+\frac{g}{C^{2}} \frac{u|u|}{h}+g \frac{h}{2 \rho} \frac{\partial \rho}{\partial x}=0$

$\frac{\partial \rho}{\partial t}+\frac{\partial \rho u}{\partial x}=0$

with the boundary conditions:

$$
\begin{aligned}
& h=h_{\circ}+\frac{H_{\circ}}{2} \sin \left(\frac{2 \pi t}{T}\right) \quad \text { at } \quad x=0 \\
& u h=-q_{r} \quad \text { at } \quad x=L \\
& \rho=\rho_{\circ} \quad \text { at } \quad x=0
\end{aligned}
$$

Where $q$ is the tidal mean water level with respect to an arbitrary datum, $u$ is the cross-sectional mean velocity, $q_{r}$ is the riverine discharge per unit width, $C$ is Chezy coefficient, $H_{o}$ is the tidal range, $L$ is the estuary length, $x$ is the horizontal distance from the mouth and $t$ is time.

Based on these equations, the following dimensionless variables can be introduced as:

$$
\begin{aligned}
v & =\frac{u}{\sqrt{g h_{\circ}}} \\
\eta & =\frac{h}{h_{\circ}} \\
\gamma & =\frac{B}{B_{\circ}} \\
\varepsilon & =\frac{g}{C^{2}} \\
\Gamma & =\frac{\rho}{\Delta \rho} \\
\xi & =\frac{x}{a} \\
\tau & =\frac{t}{T}
\end{aligned}
$$

Resonance length can be defined as:

$L_{R}=\frac{1}{4} T \sqrt{g h}$ 。

Replacing Eqs. 11-18 into Eqs. 5-10 yields to the following equations:

$\gamma \frac{a}{4 L_{R}} \frac{\partial \eta}{\partial \tau}+\frac{\partial(\gamma \eta v)}{\partial \xi}=0$

$\frac{a}{4 L_{R}} \frac{\partial v}{\partial \tau}+v \frac{\partial v}{\partial \xi}+\frac{\partial \eta}{\partial \xi}+\varepsilon \frac{a}{h_{\circ}} \frac{v|v|}{\eta}+\frac{\eta}{2 \Gamma} \frac{\partial \Gamma}{\partial \xi}=0$

$\frac{a}{4 L_{R}} \frac{\partial \Gamma}{\partial \tau}+\frac{\partial \Gamma v}{\partial \xi}=0$

with the boundary conditions as:

$$
\begin{aligned}
& \eta=1+\frac{H_{\circ}}{2 h_{\circ}} \sin (2 \pi \tau) \quad \text { at } \quad \xi=0 \\
& v \eta=-\frac{q_{r}}{h_{\circ} \sqrt{g h_{\circ}}} \quad \text { at } \quad \xi=\frac{L}{a}
\end{aligned}
$$




$$
\Gamma=\Gamma_{。} \quad \text { at } \quad \xi=0
$$

Therefore, solutions for $\eta, v$ and $\Gamma$ result in:

$$
\begin{aligned}
& \eta=\frac{h}{h_{\circ}}=\eta\left(\xi, \tau ; \gamma, \frac{L_{R}}{a}, \frac{h_{\circ}}{a}, \frac{g}{C^{2}}, \frac{H_{\circ}}{h_{\circ}}, \frac{q_{r}}{h_{\circ} \sqrt{g h}}, \Gamma, \frac{L}{a}\right) \\
& v=\frac{u}{\sqrt{g h}}=v\left(\xi, \tau ; \gamma, \frac{L_{R}}{a}, \frac{h_{\circ}}{a}, \frac{g}{C^{2}}, \frac{H_{\circ}}{h_{\circ}}, \frac{q_{r}}{h_{\circ} \sqrt{g h}}, \Gamma, \frac{L}{a}\right) \\
& \Gamma=\frac{\rho}{\Delta \rho}=\Gamma\left(\xi, \tau ; \gamma, \frac{L_{R}}{a}, \frac{h_{\circ}}{a}, \frac{g}{C^{2}}, \frac{H_{\circ}}{h_{\circ}}, \frac{q_{r}}{h_{\circ} \sqrt{g h_{\circ}}}, \Gamma \circ \frac{L}{a}\right)
\end{aligned}
$$

At HWS and/or LWS the above equation can be rewritten as:

$$
\Gamma=\frac{\rho}{\Delta \rho}=\Gamma\left(\frac{x}{a}, \gamma, \frac{L_{R}}{a}, \frac{h_{\circ}}{a}, \frac{g}{C^{2}}, \frac{H_{\circ}}{h_{\circ}}, \frac{q_{r}}{h_{\circ} \sqrt{g h_{\circ}}}, \Gamma, \frac{L}{a}\right)
$$

At the limit of salinity intrusion in both LWS and HWS, the salinity of the water is approximately the same as the riverine water salinity and therefore, Eq. 28 will become:

$$
\frac{L_{i}}{a}=f_{i}\left(\gamma, \frac{L_{R}}{a}, \frac{h_{\circ}}{a}, \frac{g}{C^{2}}, \frac{H_{\circ}}{h_{\circ}}, \frac{q_{r}}{h_{\circ} \sqrt{g h}}, \frac{\Delta \rho \circ}{\rho}, \frac{L}{a}\right)
$$

Where $i=1,2$ indicating the two different states for LWS and HWS. In Eq. 29, the first parameter is the width of estuary divided by the width at the mouth. This parameter can be well stated by geometric convergence length. Since the convergence length of cross-sectional area is used in the both side of Eq. 29, this parameter can be eliminated from Eq. 29. Furthermore, the last parameter in Eq. 29 that comes from Eq. 23 shows that the riverine Froude number must be computed at the end of estuary. Assuming constant riverine discharge and depth, the riverine Froude number at the end of an estuary is related to that of the estuary mouth and then the riverine Froude number can be determined at the estuary mouth. In this way, the final form of the functional relationship arrived from the scaling can be simplified as:

$$
\frac{L_{i}}{a}=f_{i}\left(\frac{L_{R}}{a}, \frac{h_{\circ}}{a}, \frac{g}{C^{2}}, \frac{H_{\circ}}{h_{\circ}}, \frac{q_{r}}{h_{\circ} \sqrt{g h}}, \frac{\Delta \rho_{\circ}}{\rho}\right)
$$

As the difference between salinity intrusion lengths at LWS and HWS is the same as the tidal excursion length, then:

$$
\frac{E}{a}=\frac{L^{H W S}}{a}-\frac{L^{L W S}}{a}=f\left(\frac{L_{R}}{a}, \frac{h_{\circ}}{a}, \frac{g}{C^{2}}, \frac{H_{\circ}}{h_{\circ}}, \frac{q_{r}}{h_{\circ} \sqrt{g h}}, \frac{\Delta \rho_{\circ}}{\rho}\right)(31)
$$

In which $\frac{E}{a}$ is called the tidal excursion number and the dimensionless parameters on the right-hand side of Eq. 31 are called the resonance number, the estuary shape number, the roughness number, the tidal range number, the riverine Froude number and the density number, respectively. It should be noted that Savenije (1993) showed that the estuary shape number is a good indicator for shape of the intrusion curve. He also used the tidal range number to characterize the salinity intrusion in the alluvial estuaries.

\section{Study area}

The Limpopo River estuary was used in this study as the base case study. This estuary (Fig. 1) emanates from Botswana and drains a large part of Transvaal in South Africa and the southeastern part of Zimbabwe and flows into the Indian Ocean at the city of Xai-Xai in Mozambique (Savenije, 1992; UNEP, 2005). Theriver experiences high stream flow variability characterized by flooding after intense rainfall and extreme low flows during severe droughts (Ashton et al., 2001). In Mozambique, three important tributaries connect to the Limpopo River: the Nuanedzi River, the Changane River and the Elephants River (SARDC, 2003). Limpopo estuary is alluvial and its cross-sectional areas decrease exponentially landward. The depth is approximately constant along the entire estuary. The cross-sectional area and width convergence lengths are $50 \mathrm{~km}$ (Savenije, 1993). Salinity intrusion in the estuary is usually measured up to $55 \mathrm{~km}$ upstream and up to $80 \mathrm{~km}$ during droughts (Anon Mozambique, 2006).

\section{Numerical model description}

Numerical models are useful tools for assessment of environmental impacts of anthropogenic and natural changes in estuaries. They have been successfully utilized to simulate and predict the hydrodynamic and water quality in coastal water bodies (Abbaspour and Shojaee, 2009; Moshfeghi et al., 2005; Etemad-Shahidi et al., 2008, An et al., 2009). The numerical simulations were performed with a laterally averaged two- 


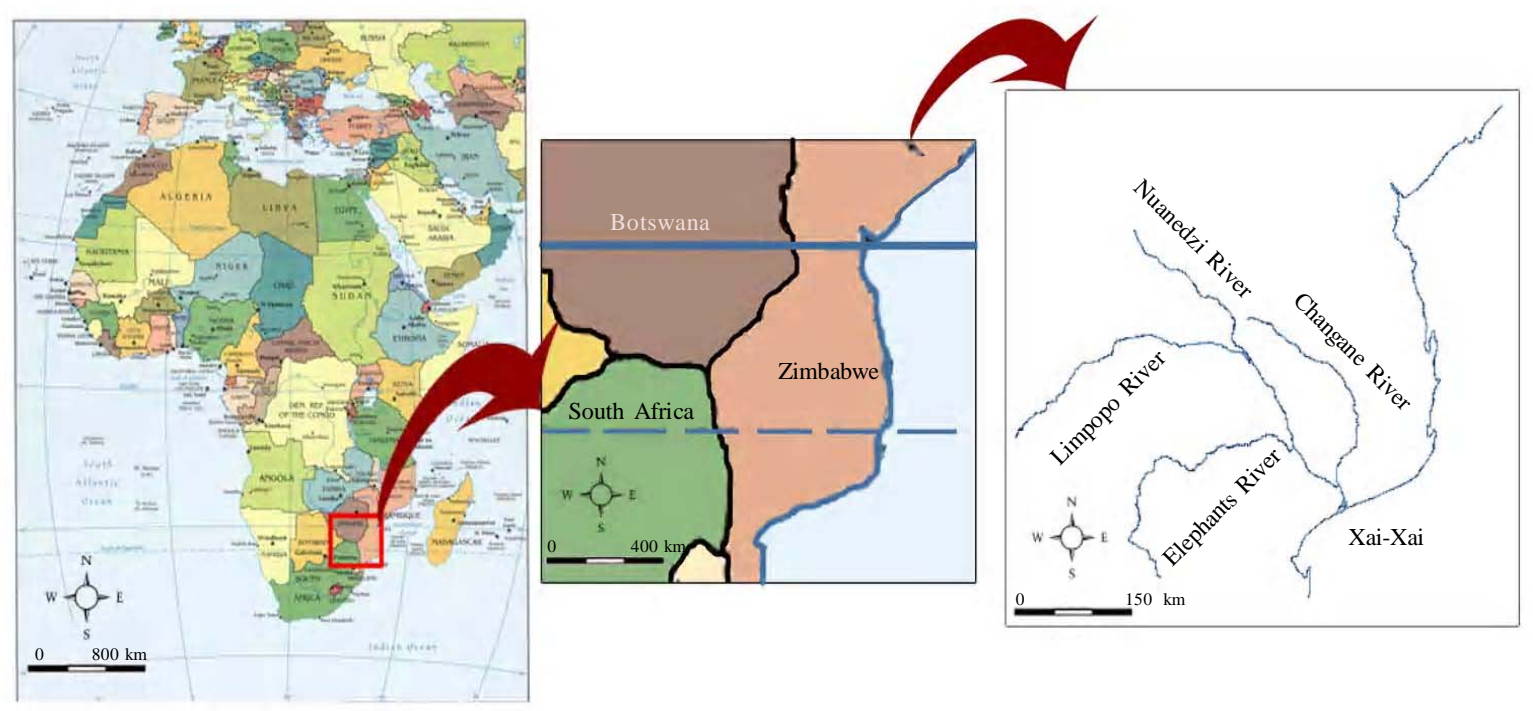

Fig. 1: Limpopo estuary map and its main tributaries

dimensional model, named CE-QUAL-W2. This model is a longitudinal-vertical hydrodynamic and transport model developed for long-term, time-varying water quality simulations that handle variable density effects on the flow field. It has been widely used in modeling of estuaries and lakes (Kurup et al., 2000; Bown and Hieronymus, 2003; Zahed et al., 2008; Etemad-shahidi et al., 2009). The model uses several zero-equation and two-equation turbulence closure schemes to represent vertical mixing in estuarine water bodies. The governing equations of the model are given by Cole and Wells (2008).

The required data to reproduce estuarine dynamics comprised of the estuary bathymetry and boundary conditions both at the estuary head and at the mouth. The discretized domain consisted of $130 \times 14$ cells so that the estuary was resolved by 130 grid cells along its axis and 14 grid cells in the vertical direction. The total length of the estuary is $130 \mathrm{~km}$ and the bottom friction was parameterized using Chezy coefficient.

\section{RESULTS AND DISCUSSION}

For calibration of the model, the data collected on 10 August 1994 were used. The boundary conditions at the mouth consisted of tidal levels and salinity. The tidal wave was imposed with a tidal range of $1 \mathrm{~m}$, a tidal period of $44440 \mathrm{~s}$ and the salinity was enforced as 35 ppt. The average discharge during the studied period $\left(3 \mathrm{~m}^{3} / \mathrm{s}\right.$ ) was considered as the upstream boundary condition. At the upstream boundary, the salinity of riverine water was $1.2 \mathrm{ppt}$.

Based on the bed friction coefficient reported by Savenije (1993), Chezy coefficient was imposed as 55 $\mathrm{m}^{1 / 2} / \mathrm{s}$. The measured salinity profile was used to calibrate the transport module. The model was executed for several tidal cycles to reach a quasi-steady state and was calibrated by minimizing the difference between the observed and simulated salinities. Comparison of the measured and simulated salinities is shown in Fig. 2. The root mean square relative errors (RMSREs) between the measured salinities and simulated results along the estuary at HWS and LWS were 0.11 and 0.26 , respectively. The measured salinity intrusion length was $60 \mathrm{~km}$ while the numerical results indicated a length of $60.8 \mathrm{~km}$. These results show that the model performs very well.

To verify the model, the field data of 4 April 1980 were used. For downstream boundary, $S_{o}=30 \mathrm{ppt}$ and a tide with a period of $44440 \mathrm{~s}$ and a range of $1.1 \mathrm{~m}$ were used. The averaged flow rate of $150 \mathrm{~m}^{3} / \mathrm{s}$ and a salinity of $0.3 \mathrm{ppt}$ were imposed as the upstream boundary 
conditions. The model results for the salinity distribution along the entire estuary for HWS and LWS is shown in Fig. 3. As can be seen, the simulated and observed salinity distributions are in good agreement (RMSREs of 0.11 and 0.25 for HWS and LWS, respectively). The reported salinity intrusion length was $21 \mathrm{~km}$ while the model results indicated a salinity intrusion length of $20 \mathrm{~km}$. In general, the model performed reasonably well. Hence, it can be used as a virtual laboratory to simulate the salinity intrusion in different conditions. The verified model was used as a virtual laboratory to simulate the salinity intrusion lengths in LWS and HWS to compute the tidal excursion length. The model was executed to attain to quasisteady state for a number of different values of independent parameters obtained by the previously mentioned scaling. In this way, different values of tidal amplitudes, mean water depth, roughness coefficient, riverine discharge, convergence length and salinity at the mouth were adopted. Then, six sets of scenarios were considered and tidal excursion lengths were determined in all of them. In all scenarios, one of the mentioned dimensional parameters was varied while the others were remained constant. Following, the effects of these parameters on the tidal excursion length are described in dimensionless form.

The effects of dimensionless parameters on the tidal excursion number are described and attempts are made to find the best mathematical functions that fit to the results. To achieve this purpose, the magnitudes of dimensionless parameters in Eq. 31, are computed and given in Table 1. The variation of the tidal excursion number versus each dimensionless parameter is indicated in Figs. 4 a-f.

The effect of the resonance number on the tidal excursion number was examined by changing the water depth. The logarithm of the tidal excursion number against the logarithm of the resonance number shows a mere relationship between these parameters (Fig. 4a). This relationship can be shown by a power function as $\frac{E}{a} \sim\left(\frac{L_{R}}{a}\right)^{1.22}$ with $\mathrm{R}^{2}=0.99$. This indicates that the resonance number has a governing role in the tidal excursion number.

The response of the tidal excursion number to the variation of estuary shape number was studied using the combined magnitude of different water depth and convergence lengths. Relationship between these two dimensionless parameters, as shown in Fig. 4b, can be well demonstrated by $\frac{E}{a} \sim\left(\frac{h_{\circ}}{a}\right)^{1.22}$ with $\mathrm{R}^{2}=0.99$. It is seen that the salinity intrusion number depends directly on the estuary shape number.

To indicate the effect of the roughness number on the tidal excursion number, the salinity intrusion numbers were plotted against the different roughness numbers (Fig. 4c). The results indicate that $\frac{E}{a} \sim\left(\frac{g}{C^{2}}\right)^{-0.31}$ with a high determination coefficient, i.e.

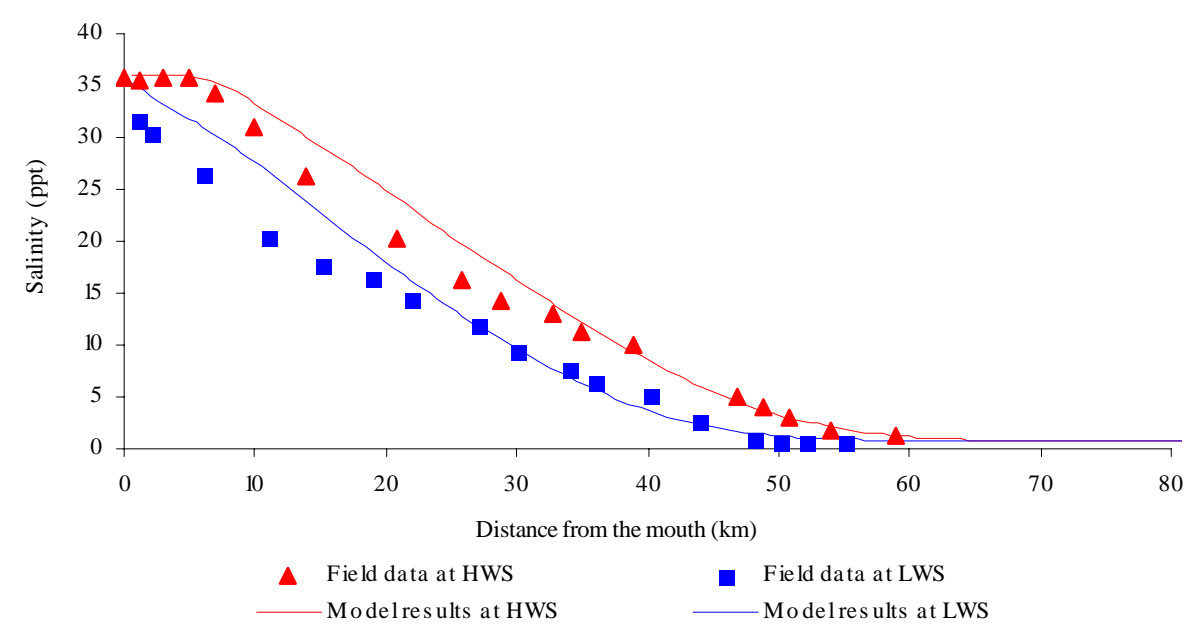

Fig. 2: Comparison of the model results and field data along the Limpopo estuary on 10 August 1994 


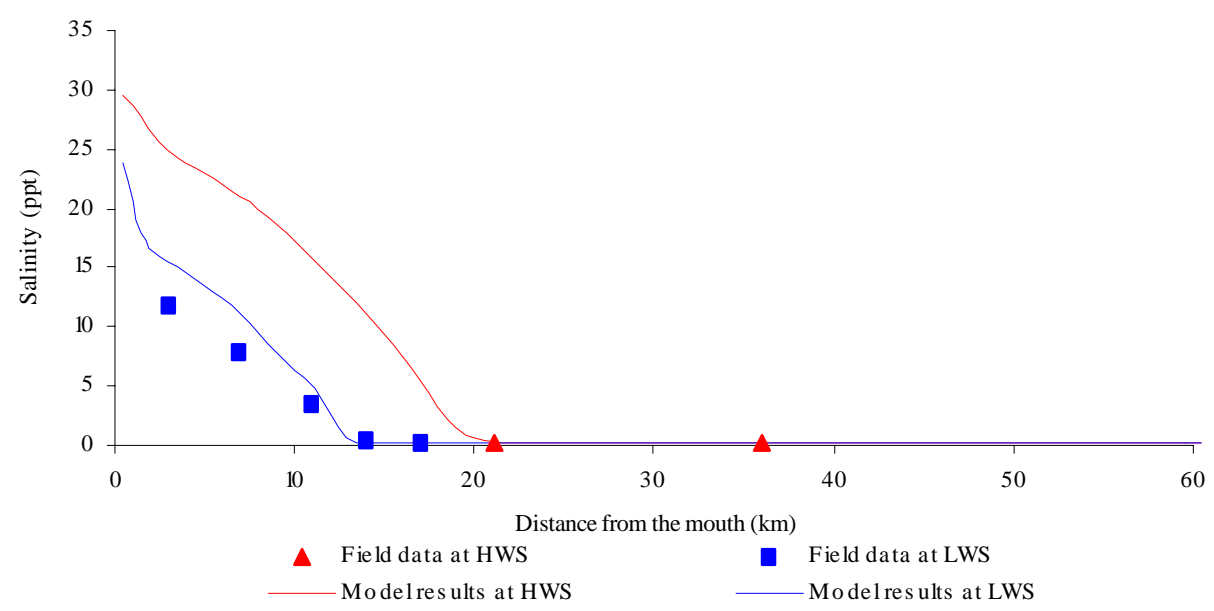

Fig. 3: Comparison of the model results and field data along the Limpopo estuary on 4 April 1980

$\mathrm{R}^{2}=0.99$.

Plotting the different values of tidal range number against the salinity intrusion number in Fig. 4d, indicates that the salinity intrusion number follows $\frac{E}{a} \sim\left(\frac{H_{\circ}}{h_{\circ}}\right)^{0.31}$ with high determination coefficient, i.e. $\mathrm{R}^{2}=0.99$. This relationship is supported by the findings of Savenije (2005). He called the tidal excursion length as the horizontal tidal range and showed the direct relationship between tidal excursion length and the tidal range.

The response of the tidal excursion number to the riverine Froude number can be expressed by $\frac{E}{a} \sim\left(\frac{q_{r}}{h_{\circ} \sqrt{g h_{\circ}}}\right)^{0.14}$ (Fig. 4e). Eq. 1 and Eq. 4 emphasize that the tidal excursion length is not affected by riverine Froude number while the obtained results in this study show a marginal effect of this parameter on the tidal excursion length. According to Eq. 1 and Eq. 4, it seems that the density difference between the seawater and the upstream riverine water has no effect on the tidal excursion length. The present study confirms this assumption. Based on the obtained results, the relationship between the tidal excursion number and the density number corresponds with $\frac{E}{a} \sim\left(\frac{\Delta \rho_{\circ}}{\rho}\right)^{0.05}$ with $\mathrm{R}^{2}=0.99$ (Fig. 4f). In addition, the values of seawater salinities are mainly in a limited range between 25 and 35 ppt. Therefore, this parameter can be eliminated from Eq. 31.

To summarize, the above-mentioned results indicate that the relationships between the tidal excursion length and the effective dimensionless parameters can be well represented by power functions. Furthermore, assessment of the resonance number and the estuary shape number implies that these two parameters are very similar. Since the resonance number includes the tidal period, which does not appear in any other dimensionless parameters, the estuarine shape number was omitted from Eq. 31. The regression analysis between the tidal excursion number and the remaining dimensionless parameters on the right-hand side of Eq. 31 implies that the following power function fits well to the results:

$$
\frac{E}{a}=7.85 \times 10^{-2}\left(\frac{L_{R}}{a}\right)^{1.11}\left(\frac{g}{C^{2}}\right)^{-0.3}\left(\frac{H_{\circ}}{h_{\circ}}\right)^{0.33}\left(\frac{q_{r}}{h_{\circ} \sqrt{g h}}\right)^{0.12}
$$

with $R^{2}=0.99$. The obtained high correlation factor indicates that the used scaling to derive the dimensionless parameters was successful.

Comparison of Eq. 32 with the previous empirical models indicates an important advantage of this equation. Firstly, Eq. 32 includes several hydraulic parameters that have not been considered previously. Secondly, this equation employs directly the tidal range value while the previous models, i.e. Eqs. (14 ), use the amplitude of tidal velocity. This is a 

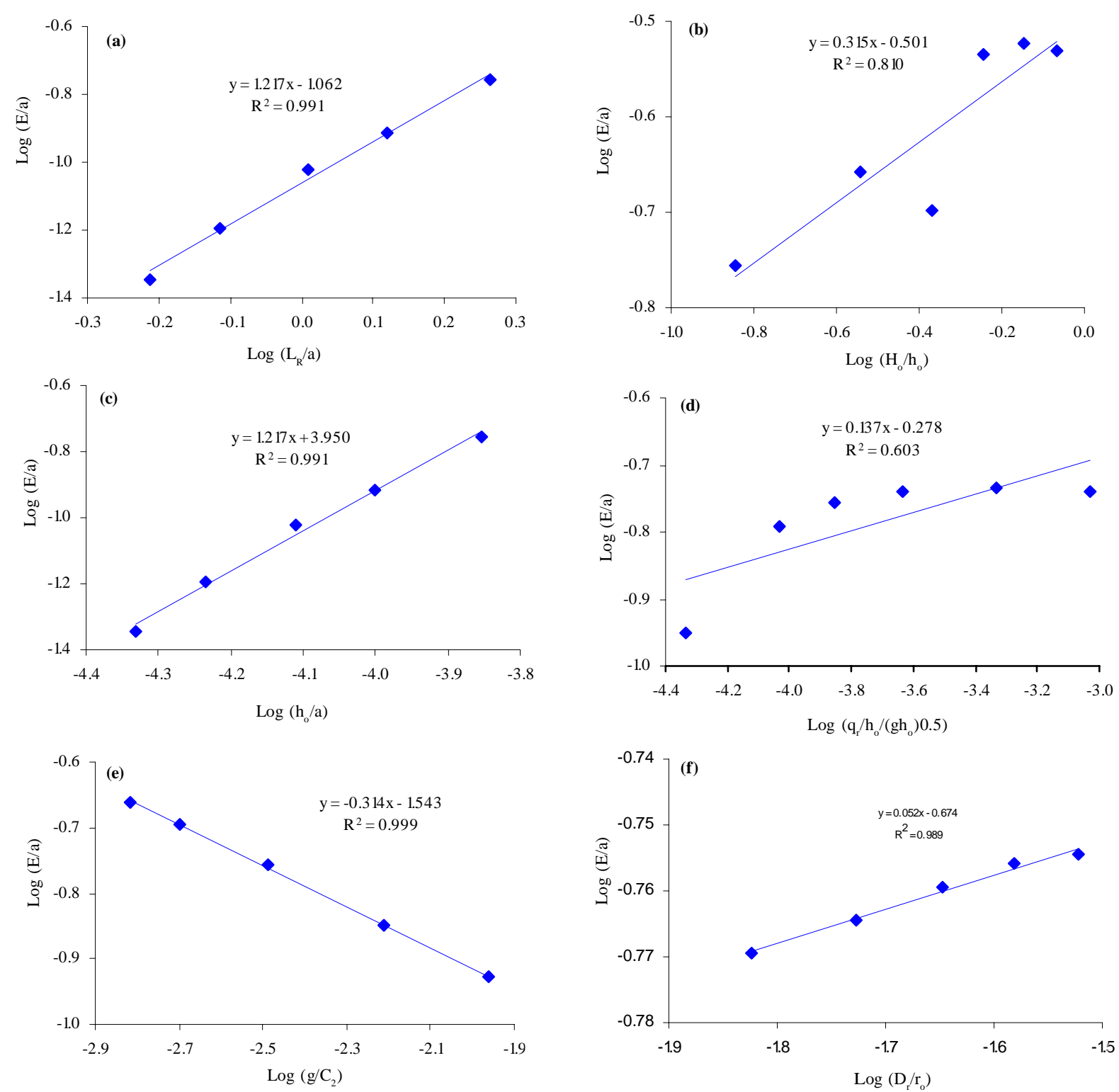

Fig. 4: Correlation between the logarithm of the tidal excursion number and the logarithm of the effective dimensionless parameters, (a) resonance number, (b) estuary shape number, (c) roughness number, (d) tidal range number, (e) riverine Froude number, (f) density number

noticeable advantage of Eq. 32 because the tidal velocity amplitude cannot be measured easily and accurately.

\section{Application of the model}

Validation of a developed model is vital to show its capability and accuracy in real conditions. To assess the validity of Eq. 32 in prediction of the tidal excursion length, several real estuaries were considered here. All selected estuaries are alluvial and therefore their crosssectional areas decrease landward. The field data of these estuaries were obtained from Savenije (1993, 2005). The required data of the estuaries and the obtained results are summarized in Table 2. The results of the presented model were then compared with the observed values and with those obtained by Eq. 4. As indicated in Figs. 5 and 6, the computed tidal excursion lengths using the presented model are in good 
Table 1: Results of scenarios for different tidal excursion lengths

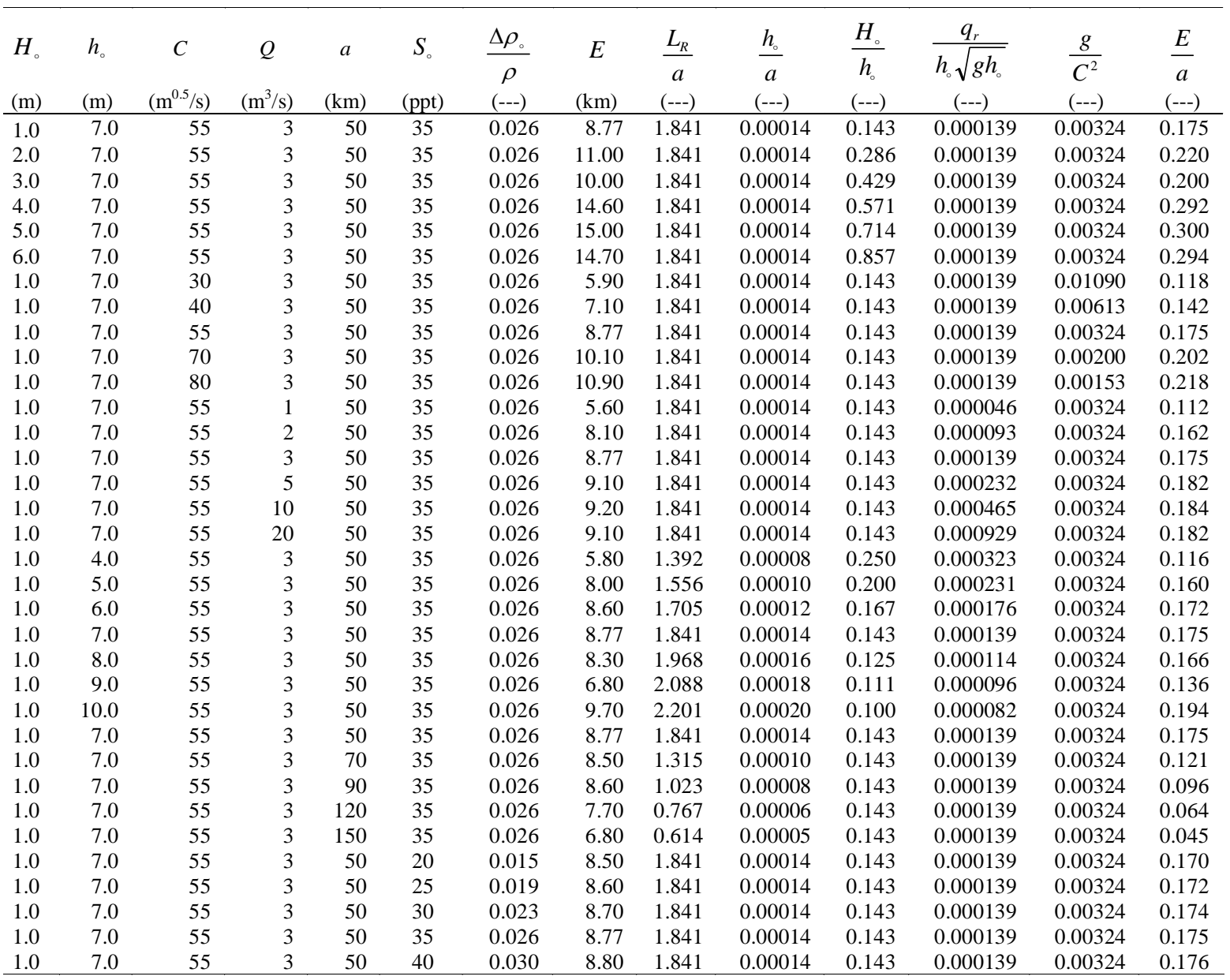

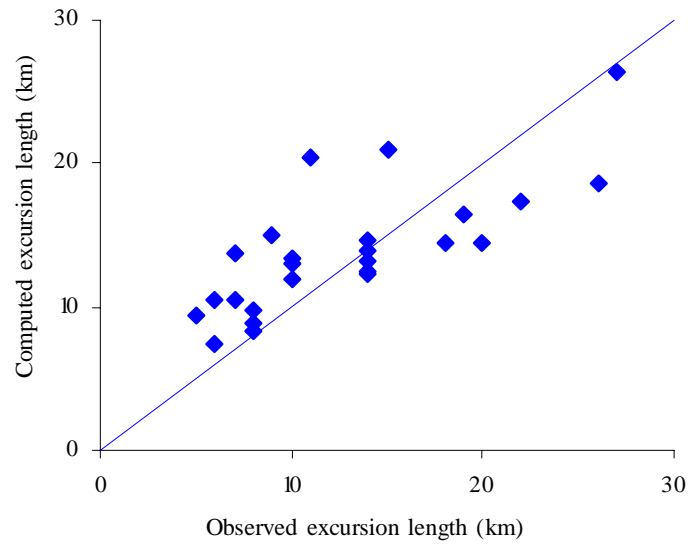

Fig. 5: Comparison of the tidal excursion length computed by Eq. 32 with the observations

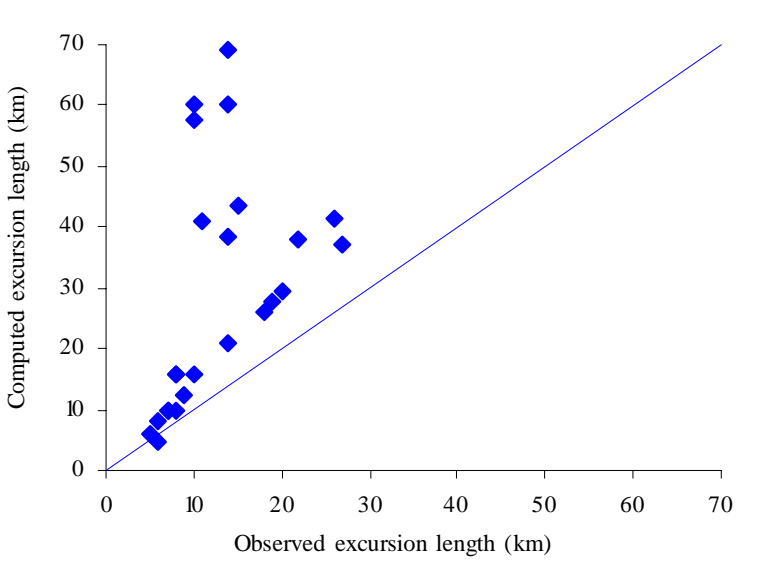

Fig. 6: Comparison of the tidal excursion length computed by Eq. 4 with the observations 
J. Parsa; A. Etemad Shahidi

Table 2: Results of the derived formula and Eq. (4) for some alluvial estuaries

\begin{tabular}{|c|c|c|c|c|c|c|c|c|c|c|c|}
\hline Estuary & Date & $\begin{array}{l}T \\
\text { (s) }\end{array}$ & $\begin{array}{l}H 。 \\
(\mathrm{~m})\end{array}$ & $\begin{array}{c}Q \\
\left(\mathrm{~m}^{3} / \mathrm{s}\right)\end{array}$ & $\begin{array}{l}h_{\circ} \\
(\mathrm{m})\end{array}$ & $\begin{array}{c}C \\
\left(\mathrm{~m}^{0.5} / \mathrm{s}\right)\end{array}$ & $\begin{array}{c}a \\
(\mathrm{~km})\end{array}$ & $\begin{array}{c}v_{\bullet} \\
(\mathrm{m} / \mathrm{s})\end{array}$ & $\begin{array}{c}E \\
(\mathrm{~km})\end{array}$ & $\begin{array}{c}E_{\text {eq. (32) }} \\
(\mathrm{km})\end{array}$ & $\begin{array}{c}E_{\text {eq. (4) }} \\
(\mathrm{km})\end{array}$ \\
\hline \multirow[t]{3}{*}{ Mae Klong } & $1977 / 01 / 20$ & 86400 & 2 & 120 & 5.2 & 63 & 102 & 1.37 & 11 & 20.5 & 40.8 \\
\hline & $1977 / 03 / 08$ & 44400 & 1.5 & 60 & 5.2 & 63 & 102 & 1.03 & 10 & 11.9 & 15.7 \\
\hline & 1977/04/09 & 44400 & 2 & 36 & 5.2 & 63 & 102 & 1.37 & 14 & 12.4 & 21.0 \\
\hline \multirow[t]{2}{*}{ Solo } & $1988 / 07 / 26$ & 86400 & 0.8 & 50 & 9.2 & 63 & 226 & 0.41 & 9 & 15.0 & 12.3 \\
\hline & 1988/09/08 & 86400 & 0.4 & 7 & 9.2 & 63 & 226 & 0.21 & 5 & 9.4 & 6.1 \\
\hline Lalang & $1989 / 10 / 20$ & 86400 & 2.6 & 120 & 10.6 & 63 & 217 & 1.25 & 27 & 26.4 & 37.1 \\
\hline \multirow[t]{5}{*}{ Limpopo } & $1979 / 10 / 18$ & 44440 & 1.1 & 18 & 7.0 & 63 & 50 & 0.65 & 7 & 10.5 & 9.9 \\
\hline & $1980 / 01 / 30$ & 44440 & 0.9 & 32 & 7.0 & 63 & 50 & 0.53 & 6 & 10.5 & 8.1 \\
\hline & $1980 / 04 / 04$ & 44440 & 1.1 & 150 & 7.0 & 63 & 50 & 0.65 & 7 & 13.7 & 9.9 \\
\hline & 1982/12/31 & 44440 & 1.1 & 10 & 7.0 & 63 & 50 & 0.65 & 8 & 9.8 & 9.9 \\
\hline & $1983 / 04 / 22$ & 44440 & 0.5 & 8 & 7.0 & 63 & 50 & 0.30 & 6 & 7.3 & 4.5 \\
\hline \multirow[t]{6}{*}{ Chao Phya } & $1962 / 06 / 05$ & 86400 & 2.2 & 63 & 7.2 & 51 & 109 & 1.28 & 22 & 17.3 & 38.1 \\
\hline & 1980/03/17 & 86400 & 1.5 & 43 & 7.2 & 51 & 109 & 0.88 & 18 & 14.5 & 26.0 \\
\hline & $1980 / 03 / 28$ & 86400 & 1.7 & 31 & 7.2 & 51 & 109 & 0.99 & 20 & 14.5 & 29.5 \\
\hline & $1983 / 01 / 29$ & 86400 & 2.4 & 90 & 7.2 & 51 & 109 & 1.40 & 26 & 18.5 & 41.6 \\
\hline & $1983 / 02 / 23$ & 86400 & 1.6 & 100 & 7.2 & 51 & 109 & 0.93 & 19 & 16.5 & 27.7 \\
\hline & $1987 / 01 / 16$ & 86400 & 2.5 & 180 & 7.2 & 51 & 109 & 1.46 & 15 & 20.9 & 43.3 \\
\hline \multirow[t]{5}{*}{ Pungue } & $1980 / 09 / 26$ & 44440 & 6.3 & 22 & 4.3 & 63 & 20 & 4.76 & 14 & 13.1 & 72.7 \\
\hline & $1982 / 05 / 26$ & 44440 & 5 & 50 & 4.3 & 63 & 20 & 3.78 & 10 & 13.4 & 57.7 \\
\hline & 1982/08/06 & 44440 & 5.2 & 36 & 4.3 & 63 & 20 & 3.93 & 10 & 13.0 & 60.0 \\
\hline & 1982/09/22 & 44440 & 5.2 & 26 & 4.3 & 63 & 20 & 3.93 & 14 & 12.5 & 60.0 \\
\hline & $1982 / 10 / 29$ & 44440 & 6 & 60 & 4.3 & 63 & 20 & 4.53 & 14 & 14.6 & 69.2 \\
\hline Thames & $1949 / 04 / 07$ & 44440 & 4.3 & 40 & 7.1 & 63 & 23 & 2.53 & 14 & 13.9 & 38.6 \\
\hline \multirow[t]{2}{*}{ Delaware } & $1932 / 08 / 23$ & 44440 & 1.7 & 120 & 6.6 & 63 & 41 & 1.04 & 8 & 8.8 & 15.8 \\
\hline & $1932 / 10 / 04$ & 44440 & 1.7 & 72 & 6.6 & 63 & 41 & 1.04 & 8 & 8.3 & 15.8 \\
\hline
\end{tabular}

agreement with the observed data (RMSRE of 42.4) while the previous model (Eq. 4) are less successful (RMSRE of 210.3) in estimation of the tidal excursion length. Since the estuaries listed in Table 2 include the wide range of estuaries around the world, this formula can be used successfully as a rapid tool for prediction of the tidal excursion length in the alluvial estuaries with well-mixed and partially-mixed salinity structure.

\section{CONCLUSION}

In the present study, the tidal excursion phenomenon under the effect of environmentally changing parameters was studied in the alluvial estuaries. First, the governing equations were scaled to arrive at the effective dimensionless parameters. Then a laterally averaged 2-D model was used in the Limpopo estuary as a case study. The model was calibrated and verified using the available field data. The verified model was then applied as a virtual laboratory to provide a synthetic data set. Acceptable correlations were obtained between effective dimensionless parameters and the tidal excursion number in the entire data set. It was also found that the tidal excursion number is very sensitive to resonance number that includes the tidal period. The relationship between the tidal excursion number and the resultant dimensionless parameters showed that the tidal excursion number can be well demonstrated by a power function. Hence, a power-law relationship was derived to predict the tidal excursion length using the simple measurable hydrologic and geometric parameters of alluvial estuaries. Application of the formula in several estuaries shows its robustness in prediction of the tidal excursion length. Unlike the previous formulae, the developed formula utilizes the tidal range instead of the tidal velocity amplitude. It is suggested to use this formula as a rapid assessment tool in different environmental conditions in unstratified alluvial estuaries.

\section{ACKNOWLEDGEMENTS}

The study reported in this research was funded partly by the deputy of research, Iran University of Science and Technology; whose support is gratefully acknowledged. 


\section{REFERENCES}

Abbaspour, M.; Mirbagheri, S. A.; Monavvari, M.; Javid, A. H.; Zarei, H., (2009). Conceptual hydrosalinity model for prediction of salt load from wastewater flows into soil and groundwater. Int. J. Environ. Sci. Tech., 6 (3), 359-368 (10 pages).

Abbaspour, M.; Shojaee, M. N., (2009). Innovative approach to design a new national low speed wind tunnel. Int. J. Environ. Sci. Tech., 6 (1), 23-34 (12 pages).

An, Q.; Wu, Y.; Taylor, S.; Zhao, B., (2009). Influence of the three gorges project on saltwater intrusion in the Yangtze river Estuary. Environ Geo., 56 (8), 1679-1686 (8 pages).

Anon, Mozambique., (2006). Mozambique national summary report on land-based activities, sources of pollution and pollutant levels in water and sediment. Draft report submitted to WIO-Lab PMU, Nairobi, Kenya.

Ashton, P. J.; Love, D.; Mahachi, H.; Dirks, P. H. G. M., (2001). An overview of the impact of mining and mineral processing operations on water resources and water quality in the Zambezi, Limpopo and Olifants catchments in Southern Africa. Contract report to the mining, minerals and sustainable development (Southern Africa) project, by SIREnvironmentek, Pretoria, South Africa and Geology Department, Uni. of Zimbabwe, Harare, Zimbabwe. Report No. ENV-P-C 2001-042. xvi + 336.

Attrill, M. J., (2002). A testable linear model for diversity trends in estuaries. J. Anim. Ecol., 71 (2), 262-269. (8 pages).

Biati, A.; Karbassi, A. R.; Hassani; A. H.; Monavari, S. M.; Moattar, F., (2010). Role of metal species in flocculation rate during estuarine mixing. Int. J. Environ. Sci. Tech., 7 (2), 327-336 (10 pages).

Bown, J. D.; Hieronymus, J. W., (2003). A CE-QUAL-W2 model of Neuse Estuary for total maximum daily load development. J. Water Resour. Plan. Manag., 129 (4), 283294. (12 pages).

Cole, T. M.; Wells, S. A., (2008). CE-QUAL-W2: A two dimensional, laterally averaged hydrodynamic and water quality model. Version 3.6, User Manual, Prepared for U.S Army Corps of Engineers Waterway Experiment Station.

Dyer, K., (1986). Coastal and estuarine sediment dynamics. Wiley, Chinchester, UK, 132-159.

Etemad-Shahidi, A.; Dorostkar, A.; Liu, W. C., (2008). Prediction of salinity intrusion in danshuei estuarine system. Hydrol. Resour., 38 (5-6), 497-505 (7 pages).

Etemad-Shahidi, A.; Afshar, A.; Alikia, H.; Moshfeghi, H., (2009). Total Dissolved Solid Modeling; Karkheh Reservoir Case Example. Int. J. Environ. Res., 7 (3), 671-680 (10 pages).

Fischer, H. B., (1974). Discussion of minimum length of salt intrusion in estuaries by Rigter, B. P., 1973. J. Hydrol. Div. Proc. ASCE, 100, 708-712 (5 pages).

Hibma, A.; de Vriend, H. J.; Stive, M. J. F., (2003). Numerical modeling of shoal pattern formation in well-mixed elongated estuaries. Estuar. Coast. Shelf Sci., 57 (5-6), 981-991 (11 pages).

Jassby, A.; Kimmerer, W.; Monismith, S.; Armor, C.; Cloern, J.; Powell, T.; Schubel, J.; Vendlinski, T., (1995). Isohaline position as a habitat indicator for estuarine populations. Ecol. Appl., 5 (1), 272-289 (18 pages).
Karbassi, A. R.; Nouri, J.; Ayaz, G. O., (2007). Flocculation of trace metals during mixing of Talar river water with Caspian Seawater. Int. J. Environ. Res., 1 (1), 66-73 (8 pages).

Kho, F. W. L.; Law, P. L.; Lai, S. H.; Ngu, L. H.; Oon, Y. W.; Ting, H. S., (2009). Quantitative dam break analysis on a reservoir earth dam. Int. J. Environ. Sci. Tech., 6 (2), 203210 (8 pages).

Krantz, W. B., (2007). Scaling analysis in modeling transport and reaction processes: A systematic approach to model building and the art of approximation, John Wiley and Sons Inc., 7-45.

Kurup, R. G.; Hamilton, D. H.; Phillips R.L., (2000). Comparison of two 2-dimensional, laterally averaged hydrodynamic model applications to the Swan River Estuary. Math. Comp. in Simul., 51 (6), 627-638 (12 pages).

Lindeboom, H., (2002). The coastal zone: An ecosystem under pressure, in: Field, J. G., Hempel, G., Summerhayes, C. (Eds.), Oceans 2020: Science, trends, and the challenge of sustainability. Island Press, Washington.

Mirbagheri, S. A.; Hashemi Monfared, S. A., (2009). Pesticide transport and transformation modeling in soil column and groundwater contamination prediction. Int. J. Environ. Sci. Tech., 6 (2), 233-242 (10 pages).

Moshfeghi, H.; Etemad-Shahidi, A.; Imberger, J., (2005). North pine dam destratification analysis. J. Wat. Sup. Res. Tech., 54, 37-46 (10 pages).

Mooraki, N.; Esmaeli Sari, A.; Soltani, M.; Valinassab, T., (2009). Spatial distribution and assemblage structure of macrobenthos in a tidal creek in relation to industrial activities. Int. J. Environ. Sci. Tech., 6 (4), 651-662 (12 pages).

Nouri, J.; Danehkar, A.; Sharifipour, R., (2008). Evaluation of ecotourism potential in the northern coastline of the Persian Gulf Environ. Geo., 55 (3), 681-686 (6 pages).

Nouri, J.; Fatemi, M. R.; Danekar, A.; Fahimi F. G.; Karimi, D., (2009). Determination of environmentally sensitive zones along Persian Gulf coastlines through geographic information system. J. Food, Agri. Environ., 7 (2), 718-725 (8 pages).

Panjeshahi, M. H.; Ataei, A., (2008). Application of an environmentally optimum cooling water system design in water and energy conservation. Int. J. Environ. Sci. Tech., 5 (2), 251-262 (12 pages).

Parsa, J.; Etemad-Shahidi, A.; Hosseiny, S.; Yeganeh-Bakhtiary, A., (2007). Evaluation of computer and empirical models for prediction of salinity intrusion in the Bahmanshir estuary. J. Coastal. Res., Special Issue, 50, 658-662 (5 pages).

Prandle, D., (1986). Generalised theory of estuarine dynamics in: Van de Kreeke (Ed.), Physics of shallow estuaries and bays. Springer-Verlag, Berlin.

Rigter, B. P., (1973). Minimum length of salt intrusion in estuaries. J. Hydr. Div. Proc. ASCE, 99, 1475-1496 (22 pages).

Reinert, T. R.; Peterson, J. T., (2008). Modeling the effects of potential salinity shifts on the recovery of striped bass in the Savannah river estuary, Georgia-South Carolina, United Sates. Environ. Manag., 41 (5), $753-765$ (13 pages).

SARDC, (2003). Limpopo river basin-Factsheet 1. SADC Water Sector.

Savenije, H. H. G., (1992). Rapid assessment technique for salt intrusion in alluvial estuaries, IHE Report. Series 27, Delft, Netherlands, 127-152. 
Savenije, H. H. G., (1993). Predictive model for salt intrusion in estuaries. J. Hydrol., 148 (1-4), 203-218 (16 pages).

Savenije, H. H. G., (2005). Salinity and tides in Alluvial Estuaries, Elsevier, Amsterdam, 108-178.

Schramkowski, G. P.; Schuttelaars, H. M.; de Swart, H. E., (2002). The effect of geometry and bottom friction on local bed forms in a tidal embayment. Cont. Shelf Res., 22 (11-13), 1821-1833 (13 pages).

Schuttelaars, H. M.; Schramkowski, G. P.; de Swart, H. E., (2004). Nonlinear channel-shoal dynamics in long tidal embayments. Ocean Dyn., 54 (3), 399-407 (9 pages).

Sundararajan, M.; Natesan, U., (2010). Geochemistry of elements in core sediments near point claimere, the Southeast Coast of India. Int. J. Environ. Res., 4 (3), 379394 (16 pages).

Thomann, R. V.; Mueller, J. A., (1987). Principles of surface water quality modeling and control. Harper and Row Pub.
Inc., New York, 478-519.

UNEP, (2005). Atlantic and Indian Oceans environment outlook., United Nations Environment Program, Nairobi. ISBN: 9280725254.

Van der Burgh, P., (1972). Ontwikkeling van een methods voor het voorspellen van Zoutverde-Lingen in estuaria, Kanalen en Zeeen. Rijkswaterstaat Rapport. 10-72.

Wright, L. D.; Coleman, J. M.; Thom, B. G., (1973). Processes of channel development in a high-tide range environment: Cambridge Gulf-Ord River Delta, Western Australia. J. Geol., 81 (1),15-41 (27 pages).

Zahed, F.; Etemad-Shahidi, A.; Jabbari, E., (2008). Modeling of salinity intrusion under different hydrological condition in Arvand River Estuary. Can. J. Civil Eng., 35 (12), 14761480 (5 pages)

Zhen-Gang, J., (2008). Hydrodynamics and water quality; modeling rivers, lakes and estuaries. John Wiley and Sons Inc., 576-580.

\section{AUTHOR (S) BIOSKETCHES}

Parsa, J., Ph.D. Scholar, School of Civil Engineering, Iran University of Science and Technology, Narmak, Tehran, Iran.

Email: jparsa@iust.ac.ir

Etemad Shahidi, A., Associate Professor, School of Civil Engineering, Iran University of Science and Technology, Narmak, Tehran, Iran. Email: etemad@iust.ac.ir

How to cite this article: (Harvard style)

Parsa, J.; Etemad Shahidi, A., (2010). Prediction of tidal excursion length in estuaries due to the environmental changes. Int. J. Environ. Sci. Tech., 7 (4), 675-686. 